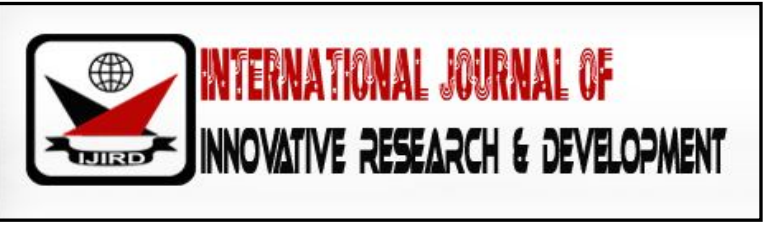

ISSN 2278 - 0211 (Online)

\title{
Design and Construction of Eight KVA Power Factor Correction Equipment
}

\begin{tabular}{c}
\hline O.M. Afolabi \\
Senior Lecturer, Department of Physics and Electronics, Adekunle Ajasin University, Nigeria \\
A.C. Tomiwa \\
Lecturer, Department of Physics and Electronics, Adekunle Ajasin University, Nigeria \\
E.O. Ogunniyi \\
Ph.D. Student, Department of Physics and Electronics, Adekunle Ajasin University, Nigeria
\end{tabular}

\begin{abstract}
:
A single-phase power factor correction equipment 8KVA power output range has been designed, constructed and tested on eight different electrical loads with the interest of providing cheaper imported alternative electrical power factor increase system for lowering cost of using electricity. The power factor correction equipment consists of DC charge control with low battery shutdown, SG3524 PWM Oscillator circuit with twenty IRFP 260 MOSFETs for no input mains AC test or use, a centre tapped and an autotransformer protected with transistors relay section. The correcting unit incorporates two $2.2 \mu \mathrm{F}, 400 \mathrm{~V}$ ac capacitors with other components in series and parallel. The input ac and power factor corrected ac electrical power were tested alternatively with double pole double throw selecting switch and the results show that the constructed power factor system is eventually cheaper than the foreign manufactured PF equipment, the electrical power consumed by the applied loads are also lower than when power factors were not corrected.
\end{abstract}

Keywords: Power factor correction, circuit, relay, protection, equipment, load

\section{Introduction}

This research work focused on the construction of a single-phase 8 KVA output power factor correction (P.F.C) equipment that would be able to measure, monitor and correct low power factor of an electrical loads/appliances and display the results on LCD.

The major objectives of this research are stated below.

- To understand what power factor is and its significance to highlight the basic components used in the construction of the power factor correction device and their functions.

- To know the parameters involved in P.F. Measurements/ Corrections and Calculations

- To examine the cause of low power factor

- To examine methods of power factor correction

- To examine and understand the benefit of power factor correction

Electric power supply in a country comprises of generating units that produce electricity, over long distance: distribution lines that deliver the electricity to consumers, sub stations that connect the pieces to each other, and energy control centre to coordinate the operation of the components.

Figure 1.0 below shows a simple electric power supply system with transmission and distribution network and linkages from electricity sources to the end-users. 


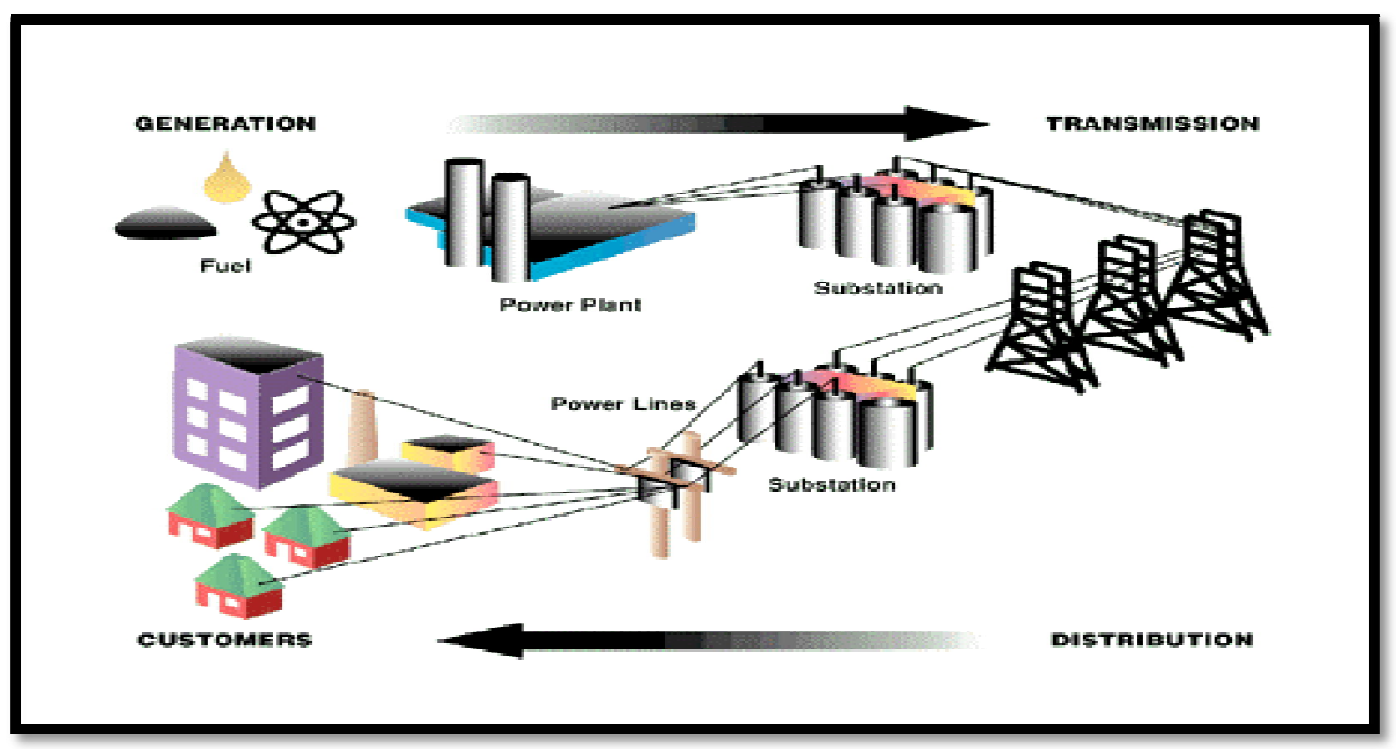

Figure 1: Typical Electric Power Supply System (Www.Powerstudies.Com, 2013)

Equipment located in consumer premises emits reactive power that lowers the power factor during power transmission. Power factor is the ratio of the power needed to do work within the consumer premises to the power delivered by the utility. The power needed by the consumer premises equipment to operate is measured in kilowatts ( $\mathrm{kW}$ ) which could also be referred to as actual power or active power or real power. The amount of the power delivered by the utility is measured in kilovolt amperes (KVA). This is also known as apparent power. It is the vectoral summation of KVAR and kW.

As mentioned earlier, appliances and machineries within consumers premise emits reactive power (KVAR) which is the power that magnetic equipment (Transformer, Motor, and Relay) needs to produce the magnetic flux. More KVAR present in the utility system results in a low power factor, and a high current (I) present on the wire. (Jinrong Quian et al, 1997, www.powerstudies.com, 2013)

\subsection{Power Factor}

Power factor is the ratio of actual power to apparent power.

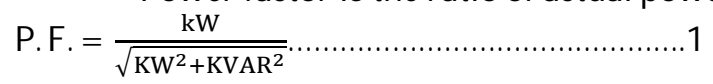

The higher the percentage of KVARs, the lower the ratio of $\mathrm{kW}$ to KVAR Thus, the lower the power factor, the lower the percentage of KVAR, the higher the ratio of $\mathrm{kW}$ to KVAR. As KVAR approaches zero, the power factor approaches 1.0. A power factor of 1.0 is ideal.

The power triangle (figure 1.2 below) illustrates the relationship between $\mathrm{kW}$, KVA, KVAR and power factor (P.F.)

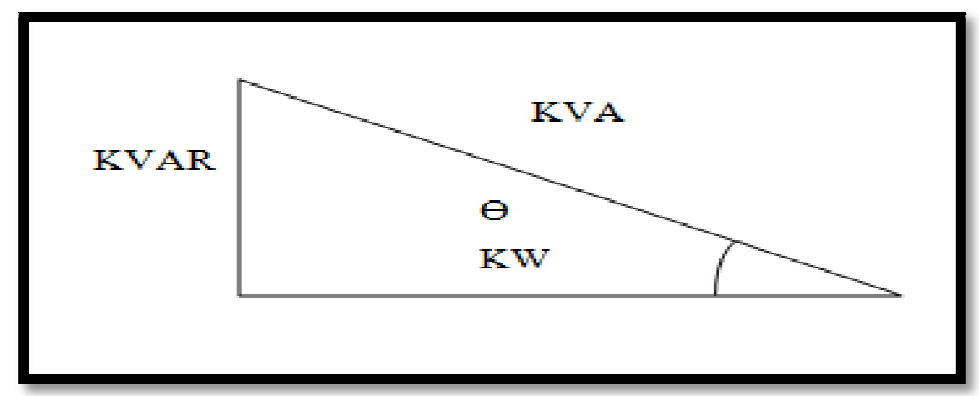

Figure 2: Relationship between KW, KVAR and Power Factor (P.F)

P.F. $=\frac{\mathrm{kW}}{\sqrt{\mathrm{kW}^{2}+\mathrm{KVAR}^{2}}}=\cos \theta$

$\frac{\mathrm{kW}}{\mathrm{KVAR}}=\sin \theta$ .3

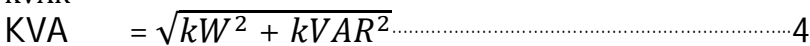

In order to have an efficient system, power factor must be closer to one (1.0) as possible.

Sometimes, electrical distribution has a power factor much less than 1.0. This came to the idea of investigating the causes of low power factor (JinrongQuian et al, 1997, Jovanovich et al, 1995, www.powerstudies.com ,2013). 


\subsection{Causes of Low Power Factor}

A poor power factor can be the result of either a significant phase difference between the voltage and current at the load terminals or it can be due to a high harmonic content or distorted/ discontinuous current waveform. Poor load current phase angle is generally the result of poor load current phase angle and is generally the result of an inductive load such as an induction motor, power transformer, lighting ballasts, welder or induction furnace, Induction generators, Wind mill generators and high intensity discharge lightings.

(Read et al,1961; Ridley 1989; www.powerstudies.com, 2013).

\subsection{Effect of Low Power Factor (P.F) in Electrical Power Transmission}

- It increases heat losses in transformers and distribution equipment,

- It reduces plant life,

- It causes unsterilized voltage levels,

- It decreases energy efficiency,

- It increases power losses,

- It increases electricity cost by paying power factor surcharges. (Ibrik et al, 2000).

Most loads on electrical distribution system fall into one of these three categories;

- Resistive

- Inductive or

- Capacitive

In most plant, the common is the inductive typically examples of this include transformers, fluorescent lighting and AC inductive motors. Most inductive loads use a conductive coil winding to produce an electromagnetic field allowing the motor function.

\subsection{Installing Capacitors for Power Factor Correction}

Installing Capacitors decrease the magnitude of reactive power (KVAR), thus increasing power factor.

A Capacitive power factor is applied to electric circuit as a means of minimizing the inductive components of the current and thereby reducing the losses in the supply.

The introduction of power factor correction capacitor is widely recognized method of reducing the electricity bill. It is not usually necessary to reach unity, i.e. power factor 1.0. By installing suitably switched capacitor into the circuit, power factor is improved and the value becomes nearer to 1.0 thus, minimizing wasted energy and improving the efficiency of electrical appliances. (Lucanu et al, 2007)

\section{Design and Construction Method of (P.F.C.) Equipment}

In this design, a $2 \times 2 \mu \mathrm{F}$ standard type A.C. switched capacitor (Non-polarity) method is adopted. This capacitor is suitable for centralized power factor correction in applications where plant loading is constantly changing resulting in the need for varying amounts of reactive power.

It is also resistant to heat and can withstand high voltage values in power transmission. An inverter and charger section are provided for alternate means of electrical supply if the remote power is off. The AC relay switching is on DC at no AC input when powered, it switches to select the AC input. The double pole double throw switch in figure 3 is a break before make switch that selects whether to measure during or after power factor correction.

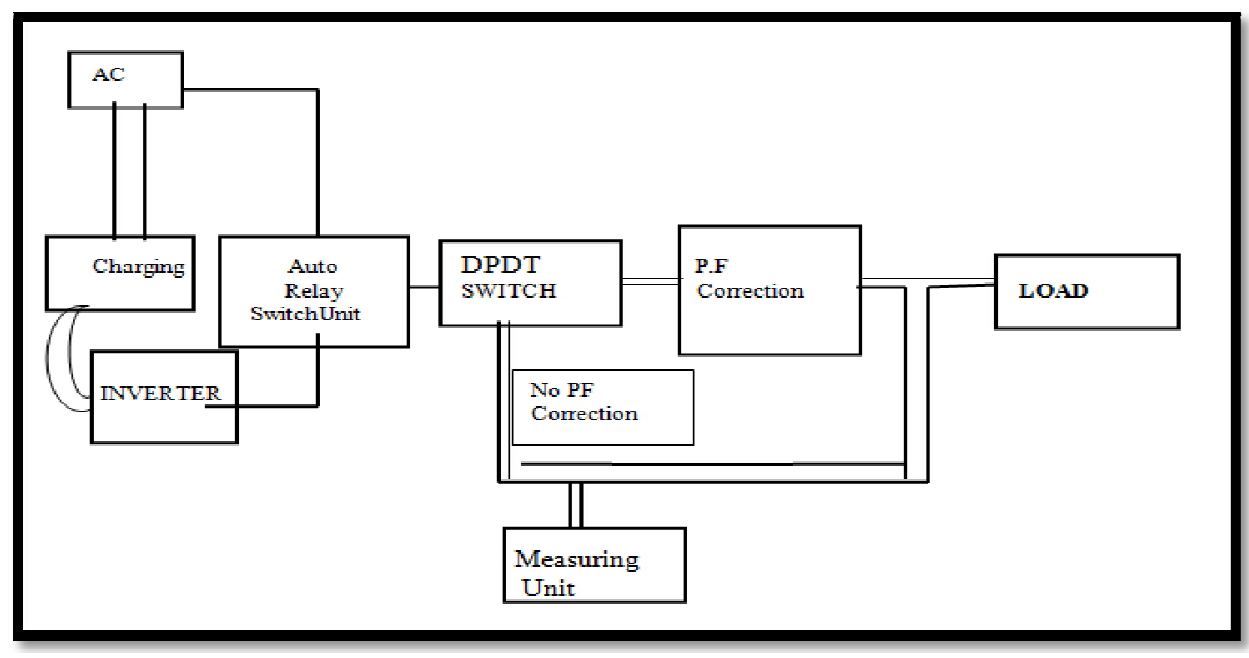

Figure 3: Power Factor Measurement Block Diagram 
The basic block diagram of figure 3 includes a DC alternative means of checking the working of and measuring power factor with the PFC circuits when AC is switched off. The double pole double throw switch also allows the selection of correction or no correction of power factor. In the power factor correction there are two series or parallel alternative methods of low P.F. correction. Figure 4 below shows the no P.F correction topology while figure 5 shows the double throw switch for measuring either the series or parallel correcting methods.

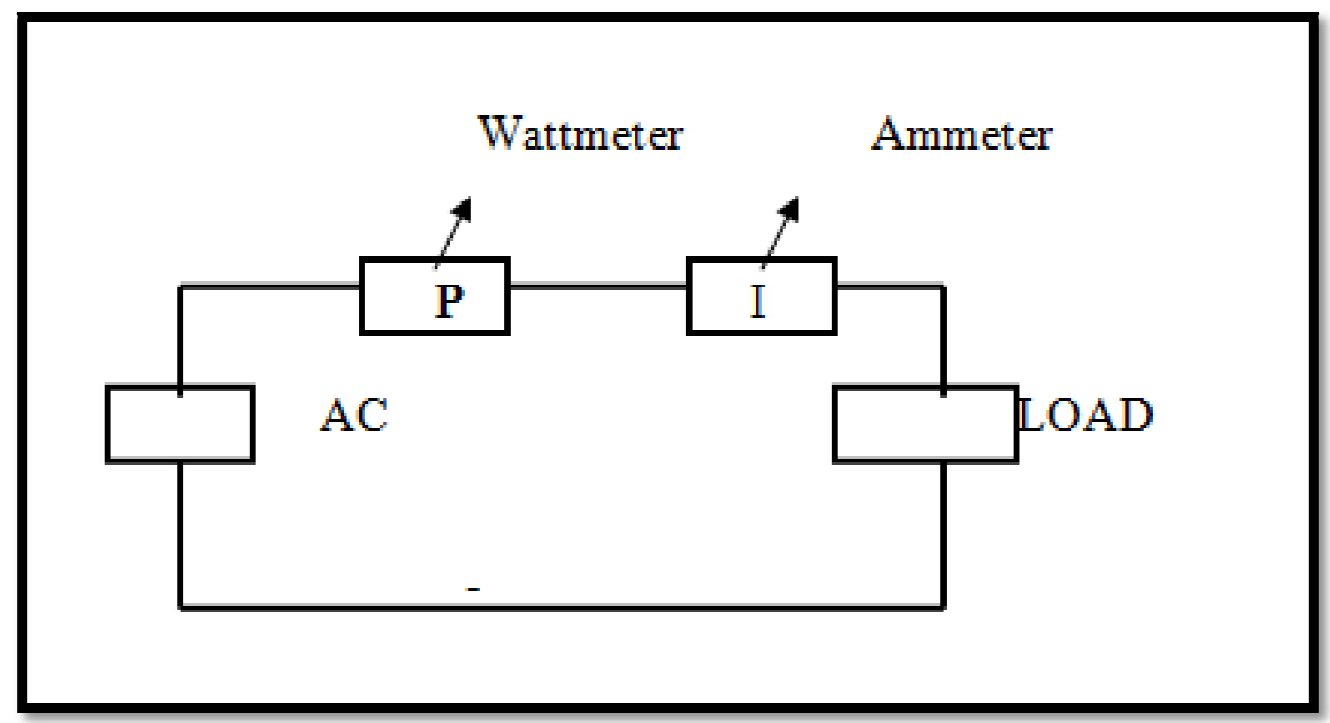

Figure 4: Circuit Arrangement Showing Non-P.F Correction (Input P.F on AC) on Load

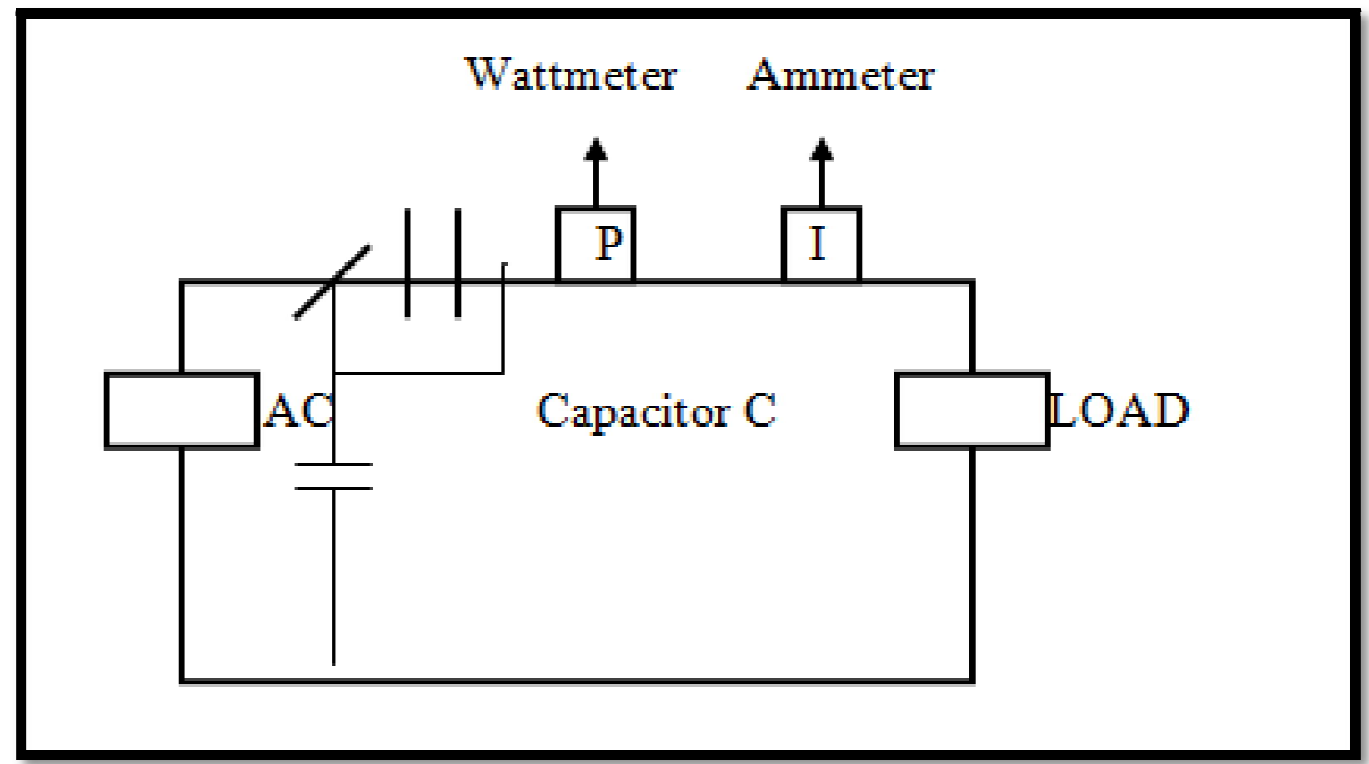

Figure 5: Circuit Arrangements for Measurement of Effect of Load on P.F for Input AC and Measurement of Correction of P.F on Loads 


\subsection{Flow Chart}

\subsubsection{Power Factor Correction Construction Flow Chart}

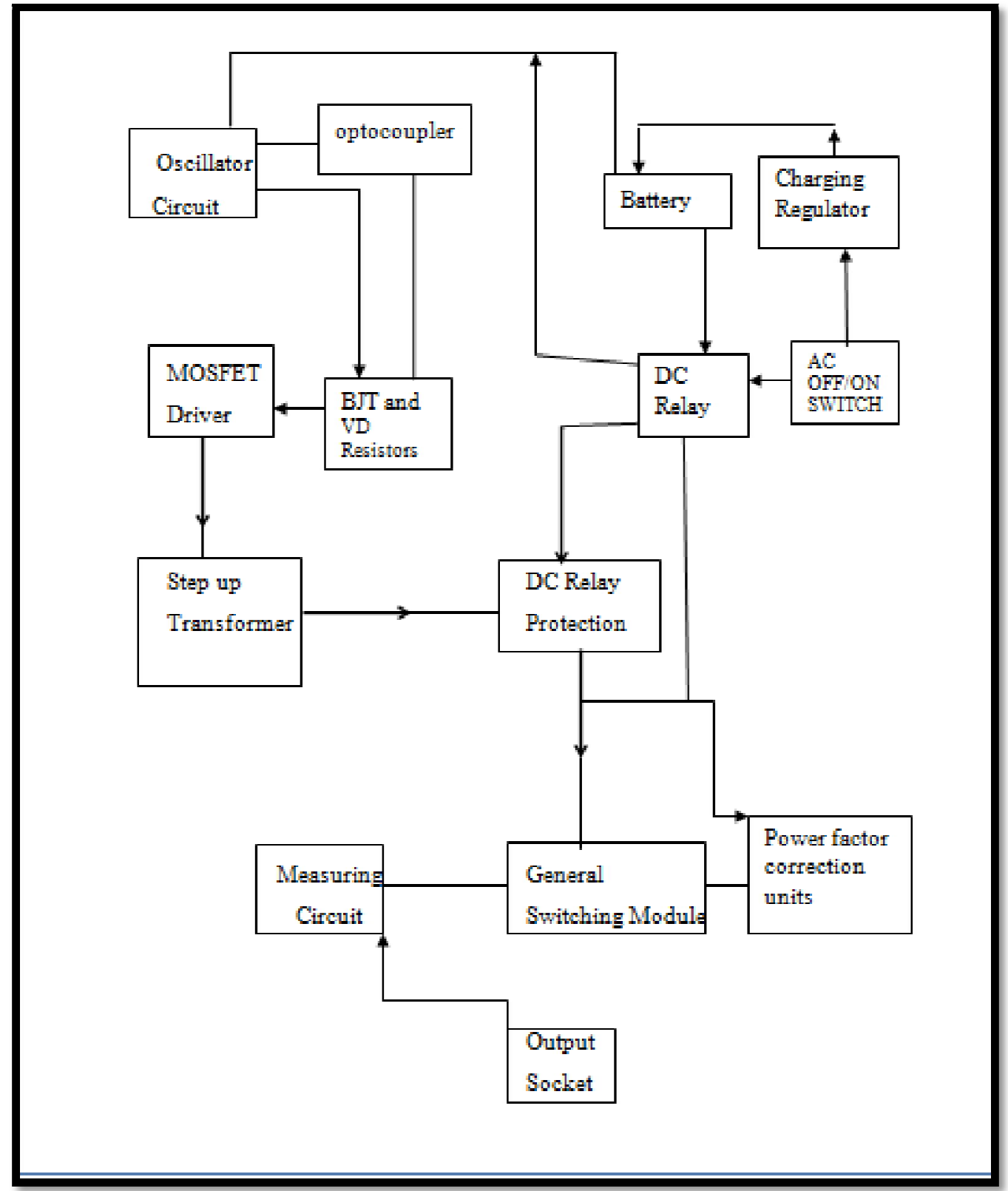

Figure 6: Flowchart Design of the Power Factor Correction Circuit

In the design of figure 6, the optocoupler is needed for monitoring voltage at SG3524 IC and gates of the MOSFET through the voltage divider resistors and the two bipolar transistors. The relay activates the low frequency DC oscillation unit to produce step up AC from the battery when there is no direct input AC. The DC relay protection circuit monitors when there is surge feedback into the transformers and it trips off during high power load measurement without which the transformers can burn. 


\subsection{Complete Circuit Diagram of Power Factor Correction Equipment}

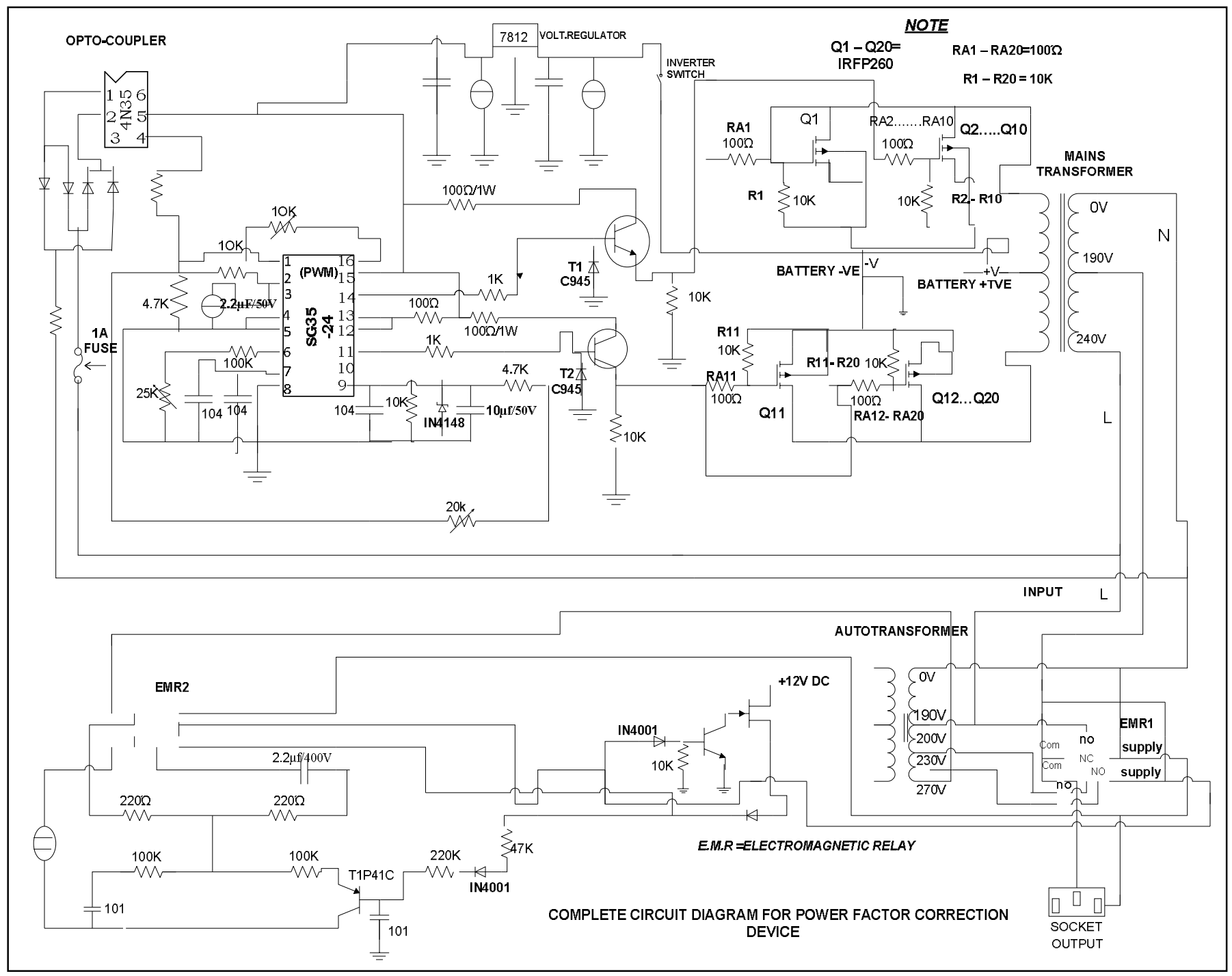

Figure 7: Complete Circuit Diagram of P.F.C Equipment

The general circuit of figure 7 contains all the detail components used in the constructing of the PFC equipment, 20 IRFP 260 are used for the $10 \mathrm{~kW}$ transformer whose centre tap connected to the positive terminal of the battery. A safe means of measuring power factor is done with the application of autotransformer and the BJT relay protecting circuits after which various loads (less than 8KVA) are connected to measure their related power factors.

\subsection{Construction of P.F.C Equipment and Measurement of P.F in Electrical Appliances}

The images of construction processes of power factor correction instrument show the use PCB method. This method provides easy fabrication of many boards as soon as the first printed circuit board is completed. The components are not dangling and circuits are durable as components cannot break off from the wire. The integrated circuits are in sockets and can easily be replaced if damaged. 


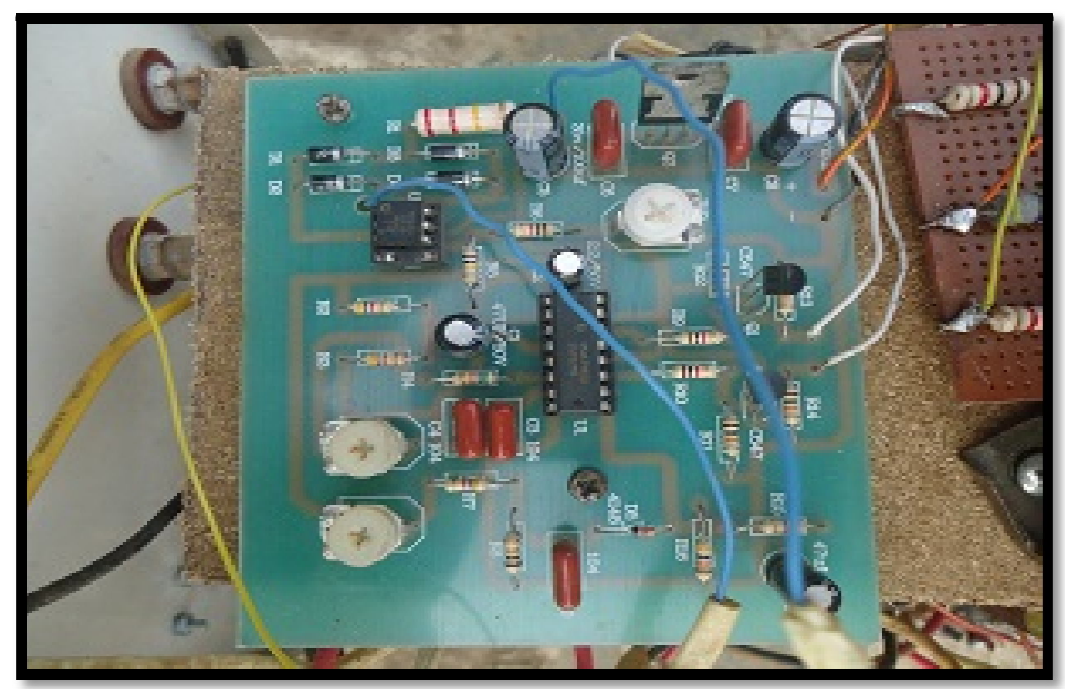

Figure 8: Inverter Unit

Figure 8 is the constructed circuits of oscillator unit (P.W.M), low battery shutdown charging regulator, opto-coupler with voltage regulator on PCB board. The centre integrated circuit is the SG3524 while the upper left IC is the optocoupler in the pulse width modulated oscillation section.

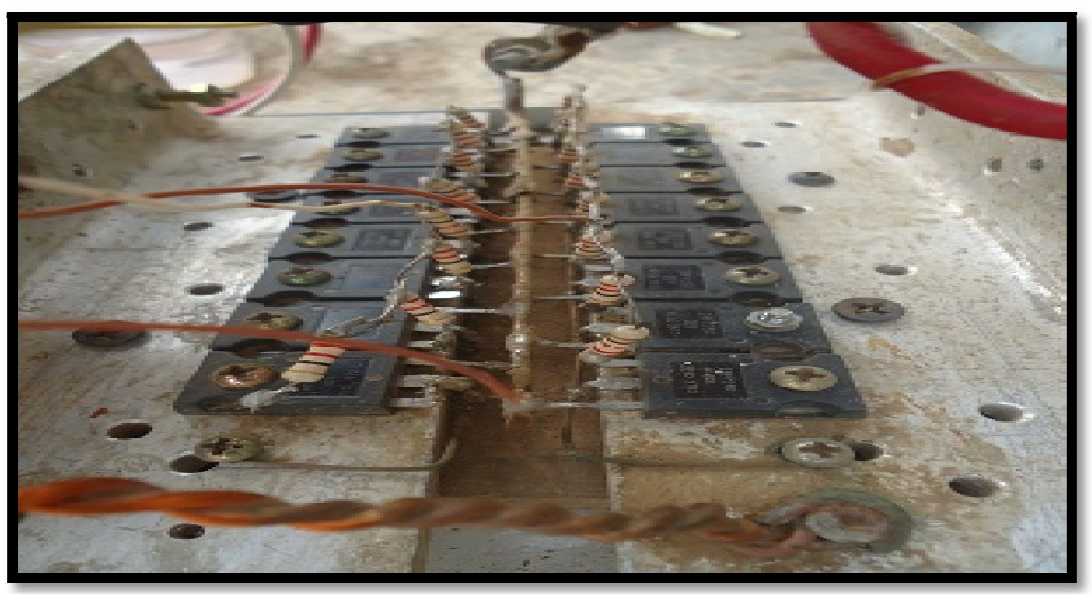

Figure 9: MOSFET Driver Unit

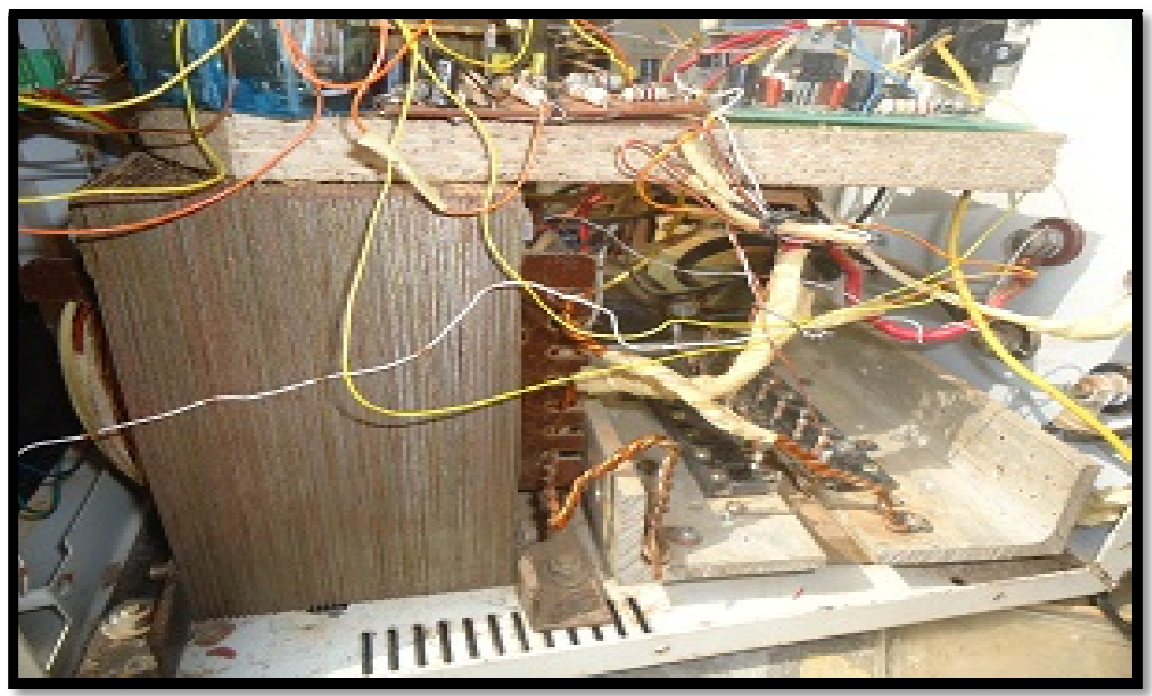

Figure 10: Power Supply Unit 
Figures 10 and 2.1 are the constructed ten pair of IRFP 260 MOSFET driver unit fixed to heat sink and 10kW step up transformer unit with PWM circuit above it to be fixed later rigidly in the casing.

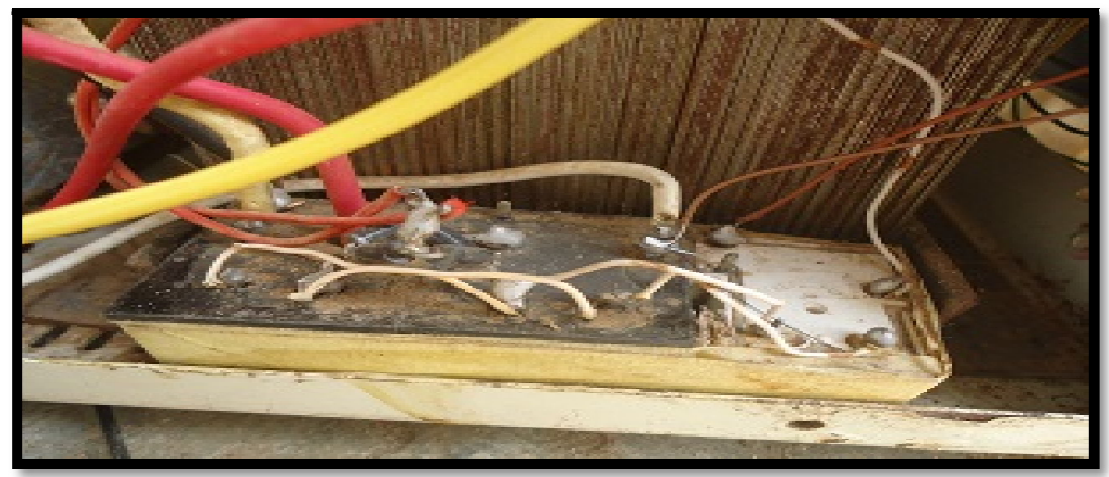

Figure 11: Changeover Unit

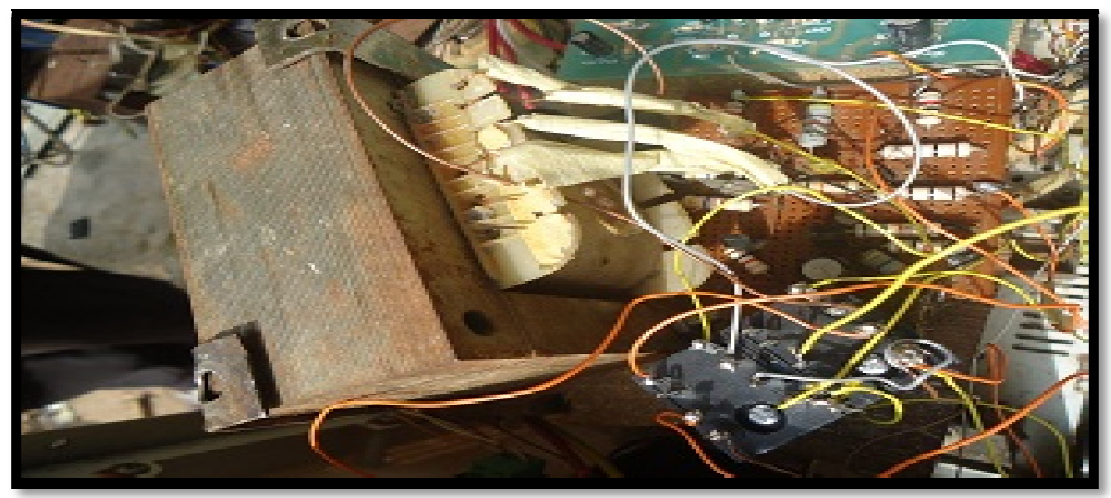

Figure 12: P.F.C Measuring Unit

Figures 11 and 12 show the constructed changeover and Power Factor measuring unit, the black component in 12 is the relay.

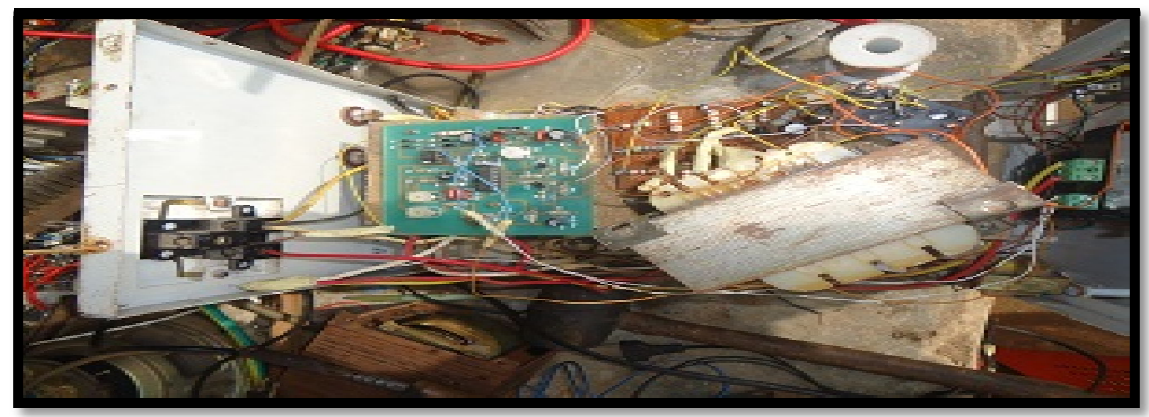

Figure 13

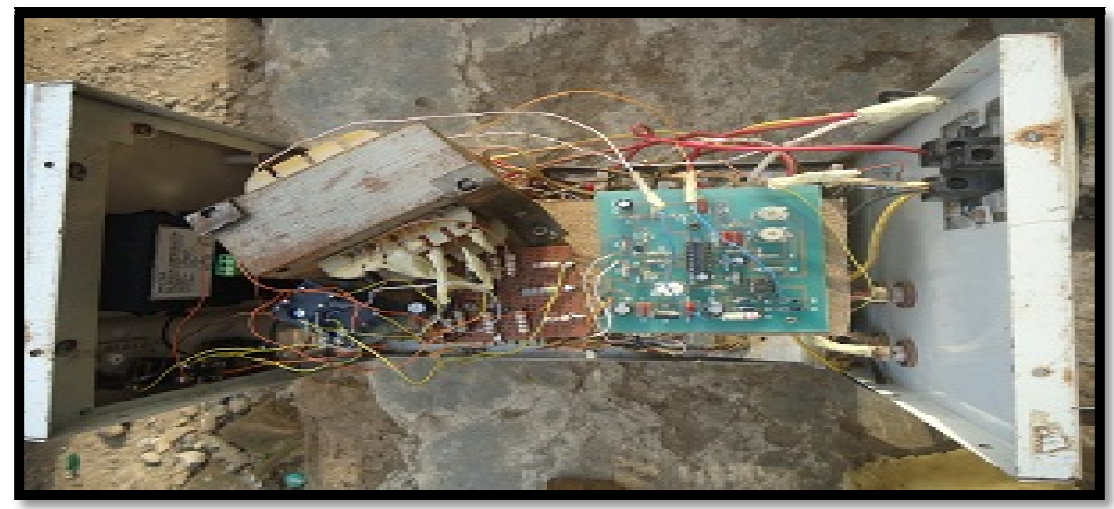

Figure 14 
Figures 13 and 14 show the assembly of Power Factor Correction various units in the painted (for electrical insulation) Metal Casing.

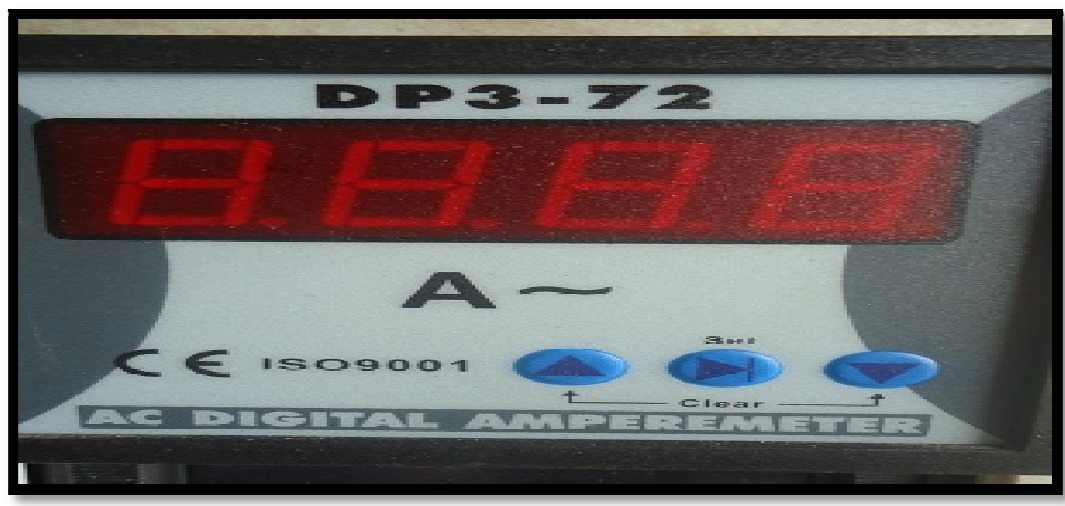

Figure 15

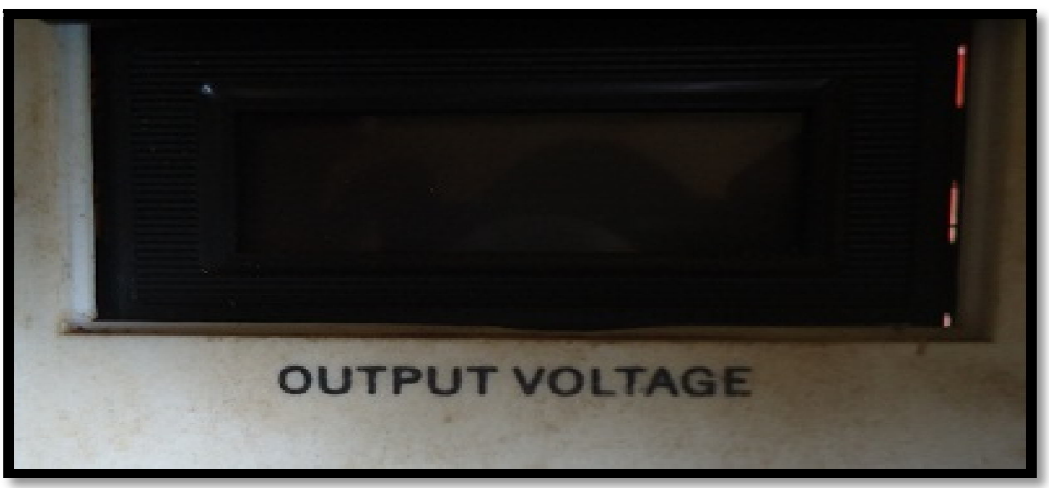

Figure 16

Figures 15 and 16 shows the separate LCD display Units consisting of Ampere meter and Voltage meter of P.F.C equipment.

\begin{tabular}{|c|c|c|c|c|}
\hline $\mathbf{S} / \mathbf{N}$ & Item Specification & Quantity & Unit Cost & Total Cost \\
\hline \multirow[t]{9}{*}{1.} & Resistors & & & \\
\hline & $1 \mathrm{k}$ & 2 & \#20 & \#40 \\
\hline & $10 \mathrm{k}$ & 20 & $\# 50$ & $\# 1000$ \\
\hline & $100 \Omega$ & 23 & $\# 20$ & \#460 \\
\hline & $100 \mathrm{k}$ & 3 & $\# 50$ & $\# 150$ \\
\hline & $220 \Omega$ & 2 & $\# 50$ & $\# 100$ \\
\hline & $220 \mathrm{k}$ & 1 & $\# 50$ & $\# 50$ \\
\hline & $4.7 \mathrm{k}$ & 2 & $\# 50$ & $\# 100$ \\
\hline & $47 \mathrm{k}$ & 1 & $\# 50$ & $\# 50$ \\
\hline \multirow[t]{4}{*}{2.} & Variable Resistors & & & \\
\hline & $10 \mathrm{k}$ & 1 & $\# 50$ & $\# 50$ \\
\hline & $25 \mathrm{k}$ & 1 & $\# 50$ & $\# 50$ \\
\hline & $20 \mathrm{k}$ & 1 & $\# 50$ & $\# 50$ \\
\hline \multirow[t]{6}{*}{3.} & Capacitors & & & \\
\hline & $2.2 \mu \mathrm{f} / 50 \mathrm{v}$ & 3 & $\# 50$ & $\# 150$ \\
\hline & $2.2 \mu \mathrm{f} / 400 \mathrm{v}$ & 1 & \#50 & \#50 \\
\hline & $10 \mu f / 50 \mathrm{v}$ & 1 & $\# 50$ & $\# 50$ \\
\hline & $101 \mu f$ & 2 & $\# 50$ & $\# 100$ \\
\hline & $104 \mu \mathrm{f}$ & 5 & $\# 50$ & $\# 250$ \\
\hline \multirow[t]{3}{*}{4.} & Transistors & & & \\
\hline & C945 & 2 & \#30 & $\# 60$ \\
\hline & T1p 41c & 2 & \#30 & $\# 60$ \\
\hline 5. & Diodes & & & \\
\hline
\end{tabular}




\begin{tabular}{|c|c|c|c|c|}
\hline $\mathbf{S} / \mathbf{N}$ & Item Specification & Quantity & Unit Cost & Total Cost \\
\hline & In4148 & 1 & $\# 50$ & \#50 \\
\hline & In4001 & 6 & $\# 50$ & $\# 300$ \\
\hline 6. & Mosfet & & & \\
\hline & Irfp260 (10k) & 20 & \#350 & $\# 7,000$ \\
\hline 7. & Optp-Coupler (4n35) & 1 & $\# 100$ & \#100 \\
\hline 8. & Volt. Regulator (Lm7812) & 1 & \#50 & $\# 50$ \\
\hline 9. & Lm339 Ic & 1 & $\# 50$ & $\# 50$ \\
\hline 10. & Sg3524 Ic & 1 & $\# 300$ & \#300 \\
\hline 11. & Relay Switch & 2 & $\# 200$ & $\# 400$ \\
\hline 12. & Dtdp Switch & 1 & $\# 100$ & $\# 100$ \\
\hline 13. & Stsp Switch & 1 & $\# 100$ & $\# 100$ \\
\hline 14. & Vero Board & 1 & \#50 & \#50 \\
\hline 15. & Pcb Board & 1 & $\# 100$ & $\# 100$ \\
\hline 16. & Ac On/ Off Switch & 1 & $\# 100$ & $\# 100$ \\
\hline 17. & Fuse (1a) & 1 & \#20 & \#20 \\
\hline 18. & Connecting Wires & & $\# 1,560$ & $\# 1,560$ \\
\hline 19. & Digital Voltmeter & 1 & $\# 2,500$ & $\# 2,500$ \\
\hline 20. & Digital Ammeter & 1 & $\# 2,500$ & $\# 2,500$ \\
\hline 21. & Ac Socket & 1 & \#150 & \#150 \\
\hline 22. & Autotransformer & 1 & $\# 12,500$ & $\# 12,500$ \\
\hline 23. & Centre-Tap Transformer & 1 & $\# 15,500$ & $\# 15,500$ \\
\hline 24. & Heat Absorber & 2 & $\# 250$ & $\# 500$ \\
\hline 25. & Soldering Lead & & $\# 500$ & $\# 500$ \\
\hline 26. & Metal Casing & & $\# 2,500$ & $\# 2,500$ \\
\hline 27. & 12v Wet Cell Battery & 2 & $\# 11,000$ & $\# 22,000$ \\
\hline 28. & Bolts And Nuts & & $\# 250$ & $\# 250$ \\
\hline 29. & Cellotape & 1 & $\# 100$ & $\# 100$ \\
\hline 30. & Painting Of Metal Casing & & $\# 800$ & $\# 800$ \\
\hline 31. & Transport & & $\# 25,650$ & $\# 25,650$ \\
\hline 32 & $\begin{array}{c}\text { Cost Of Burnt And Wasted } \\
\text { Components During Construction }\end{array}$ & & \#24,170 & \#24,170 \\
\hline & Total Cost & & & $\begin{array}{l}\text { 123,220.00 Naira } \\
\text { 779.87 Dollars }\end{array}$ \\
\hline & Cost Of Similar Equipment In Usa & & & 1129.89 Dollars \\
\hline
\end{tabular}

Table 1: Bill of Engineering Construction

Table 1 shows Bill of Engineering Construction and Cost Evaluation of the constructed P.F.C Equipment. The next similar equipment built will cost less due to lower transportation cost and reduced burnt components. The cost does not contain shipping, clearing and local transport costs which will make it more expensive than the locally constructed one. The locally constructed power factor correcting equipment power can be easily increased for more loads and can easily be repaired.

\subsection{Tests and Measurement on Power Factor in Electrical Appliances}

The following electrical appliances/ loads were selected as case study for this research work; these appliances were supplied with AC/ DC through 8 KVA power factor correction equipment at their different maximum power demand.

- $\quad$ Electric Heater (Boiling Ring)

- Desktop Computer Set

- Electric Standard Fan

- Electric Blender

- Electric Cooker

- Electric Iron

- Refrigerator

- Television Set (T.V. Set) 
The above listed electrical loads shall be tested and measured one after the other for uncorrected P.F. and for corrected P.F. The measurement and calculations of power factor (P.F.), Active power (P), Reactive power (Q), Apparent power (S) and current (I) are also required for each load applied.

2.5. Calculation of Results Using Power Factor Formula Load (1)

The following results were obtained for each load applied for power factor correction measurements.

\subsection{Electric Boiling Ring}

Before P.F.C.

Real power $(\mathrm{p})=1.2 \mathrm{kw}=1200 \mathrm{~W}$

Load voltage $($ Vrms $)=255 \mathrm{~V}$

Apparent power (s) = Vrms x Irms

$$
\mathrm{S}=255 \mathrm{v} \times 6.28 \mathrm{~A}
$$

Power factor (p.f) $=\frac{\text { Real Power }}{\text { Apparent Power }}=\frac{P}{S}$

$$
\mathrm{S}=1601.4 \mathrm{VA}
$$

Where:

$$
\begin{aligned}
& \text { p.f. }=\frac{1200}{1601.4} \\
& \text { p.f }=0.75
\end{aligned}
$$

$$
\begin{gathered}
\mathrm{KVA}=\sqrt{k W^{2}+k V A R^{2}} \quad \text { or, } \\
\mathrm{S}=\quad \sqrt{P^{2}+Q^{2}} \\
\text { Where KVAR }=\text { reactive power }(\mathrm{Q})
\end{gathered}
$$

Therefore,

$$
\begin{aligned}
& \mathrm{KVAR}_{1}=\sqrt{k V A R^{2}-k W^{2}} \\
& \mathrm{Q}_{1}=\sqrt{(1601.4)^{2}-(1200)^{2}} \\
& \mathrm{KVAR}_{1}=1060.42 \text { or } \\
& \mathrm{Q}_{1}=1.60 \mathrm{KVAR}
\end{aligned}
$$

After power factor correction

Real power $(\mathrm{p})=1200 \mathrm{~W}$

Load voltage $($ Vrms $)=220 \mathrm{~V}$

Load current $($ Irms $)=5.62 \mathrm{~A}$

Apparent power $(\mathrm{s})=(220 \times 5.62) \mathrm{VA}$

p.f $=\frac{1200}{1236.4}$

$$
\mathrm{S}=1236.4 \mathrm{VA}
$$

Therefore,

$$
\text { p.f }=0.97
$$

$\mathrm{KVAR}_{2}=\sqrt{S^{2}-P^{2}}$

$\mathrm{Q}_{2}=\sqrt{(1236.4)^{2}-(1200)^{2}}$

$\mathrm{KVAR}_{2}=297.80$ or $\quad \mathrm{Q}_{2}=0.30 \mathrm{KVA}$

Hence, the amount of power required to boost power factor from initial to required one

$=\mathrm{KVAR}_{1}-\mathrm{KVAR}_{2}$

Q required $=1060.42-297.80$

VAR required $=762.62$

These calculations were done for loads 2 to 8 and measurement results are tabulated below

\section{Results and Discussion}

\subsection{Results}

The calculated values for uncorrected and corrected power factor for each load applied for this research are further illustrated in the following tables. 


\begin{tabular}{|c|c|c|c|c|c|c|c|}
\hline S/ N & Load & $\begin{array}{c}\text { Voltage } \\
\text { (V) }\end{array}$ & P.F. & $\begin{array}{c}\mathbf{P} \\
(\mathbf{K W})\end{array}$ & $\begin{array}{c}\mathbf{Q} \\
\text { (KVAR) }\end{array}$ & $\begin{array}{c}\text { S } \\
(\mathbf{K V A})\end{array}$ & $\begin{array}{c}\text { I } \\
(\mathbf{A})\end{array}$ \\
\hline 1. & Boiling Ring & 255 & 0.75 & 1.2 & 1.06 & 1.60 & 6.28 \\
\hline 2. & Desktop Computer Set & 237 & 0.76 & 1.2 & 1.03 & 1.58 & 6.66 \\
\hline 3. & Electric Fan & 257 & 0.68 & 2.3 & 2.48 & 3.38 & 13.16 \\
\hline 4 & Electric Blender & 243 & 0.65 & 1.8 & 2.11 & 2.77 & 11.40 \\
\hline 5 & Electric Cooker & 260 & 0.77 & 1.5 & 1.24 & 1.95 & 7.49 \\
\hline 6 & Electric Iron & 253 & 0.74 & 1.2 & 1.09 & 1.62 & 6.40 \\
\hline 7 & Refrigerator & 251 & 0.78 & 2.0 & 1.61 & 2.57 & 10.23 \\
\hline 8 & T.V.Set & 230 & 0.68 & 1.1 & 1.18 & 1.61 & 7.0 \\
\hline
\end{tabular}

Table 2: Before P.F.C on AC Supply for Each Load Applied [Uncorrected Power Factor]

\begin{tabular}{|c|c|c|c|c|c|c|c|}
\hline S/ N & LOAD & $\begin{array}{c}\text { Voltage } \\
(\mathbf{V})\end{array}$ & $\mathbf{P . F .}$ & $\begin{array}{c}\mathbf{P} \\
\text { (KW) }\end{array}$ & $\begin{array}{c}\mathbf{Q} \\
\text { (KVAR) }\end{array}$ & $\begin{array}{c}\text { S } \\
\text { (KVA) }\end{array}$ & $\begin{array}{c}\text { I } \\
\text { (A) }\end{array}$ \\
\hline 1. & Boiling Ring & 220 & 0.97 & 1.2 & 0.30 & 1.24 & 5.62 \\
\hline 2. & Desktop Computer Set & 230 & 0.98 & 1.2 & 0.24 & 1.22 & 5.32 \\
\hline 3. & Electric Fan & 233 & 0.95 & 2.3 & 0.73 & 2.41 & 10.35 \\
\hline 4 & Electric Blender & 228 & 0.92 & 1.8 & 0.77 & 1.96 & 8.58 \\
\hline 5 & Electric Cooker & 240 & 0.94 & 1.5 & 0.55 & 1.59 & 6.65 \\
\hline 6 & Electric Iron & 235 & 0.98 & 1.2 & 0.23 & 1.22 & 5.20 \\
\hline 7 & Refrigerator & 230 & 0.89 & 2.0 & 1.04 & 2.25 & 9.80 \\
\hline 8. & T.V.Set & 225 & 0.96 & 1.1 & 0.32 & 1.15 & 5.09 \\
\hline
\end{tabular}

Table 3: After P.F.C on AC Supply for Each Load Applied [Corrected Power Factor]

\begin{tabular}{|c|c|c|c|}
\hline S/ N LOAD & $\begin{array}{c}\text { Real Power } \\
\text { (kW) }\end{array}$ & $\begin{array}{c}\text { Uncorrected } \\
\text { Apparent Power } \\
\text { (KVA) }\end{array}$ & $\begin{array}{c}\text { Corrected Apparent } \\
\text { Power (KVA) }\end{array}$ \\
\hline 1. & 1.2 & 1.60 & 1.24 \\
\hline 2 & 1.2 & 1.58 & 1.22 \\
\hline 3 & 2.3 & 3.38 & 2.40 \\
\hline 4 & 1.8 & 2.77 & 1.96 \\
\hline 5 & 1.5 & 1.95 & 1.59 \\
\hline 6 & 1.2 & 1.62 & 1.22 \\
\hline 7 & 2.0 & 2.57 & 2.25 \\
\hline 8 & 1.1 & 1.61 & 1.15 \\
\hline
\end{tabular}

Table 4: Table Illustrating the Real Power, Initial Apparent Power and the Required Apparent Power for Each Load Applied

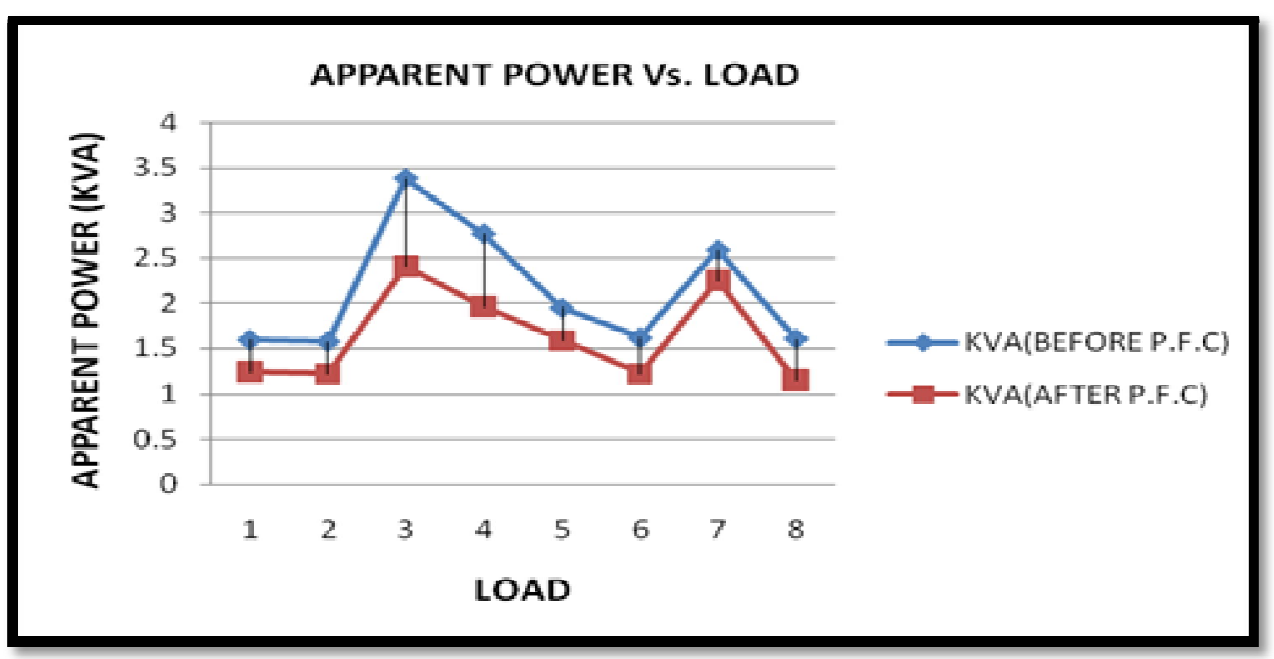

Figure 17: Apparent Powers vs. Applied Load 


\subsection{Discussion of Result}

The electrical power factor correcting equipment designed and constructed consists of inverter, changeover and protection relay circuits, series and power factor correction and measurement units from the auto transformer. The various measurements on eight electrical loads show that more electrical power is used when power factor was not corrected. The power factor correction allows the reactive power in the system to be lowered thus reducing transformer and distribution circuit loads, and the system working capacity is improved and maintained as seen in Tables 3 and 4 and figure 17 of this research.

The constructed P.F.C Power Supply;

- Improves electrical appliances efficiency,

- Extends life of electronic appliances by reducing heat stress due to higher than normal power consumption,

- Reduces overloading of cable, transformer, switches etc.

- Stabilizes voltage level in electrical system,

- Eliminates power factor penalties,

- Conserves energy,

- Reduces power loss in electrical distribution system,

- It saves some money on electrical power bill,

- Is cheaper compare to the ready-made or imported ones.

\section{Conclusion and Recommendation}

The main objective throughout the research is to increase input power factor of loads applied to an AC supply. By applying capacitor into power factor correcting circuits connected to autotransformer with relay circuits protection, the equipment is duly completing and tested with measurement justifying the need for correcting low power factor at the production just before the loads. The power of course must be increased as loading is increasing and this will add to the cost of the equipment but in the long run the cost of building power factor equipment will far outweigh the charges or bills from electrical supply companies hence it is suggested that

installation of suitable P.F.C into the input Power Supply circuit of electrical consumers should be done to reduce electrical power loss and the associated cost.

\section{References}

i. JinrongQuian and Lee F.C.,(1997) "A high efficiency single stage switch high power factor AC/ DC Converter with universal input". IEEE APEC, pp. 281 - 287.

ii. Jovanovich M.M, Lee F.C, Yimin Jiang and Zhang M.T. (1995) , "single - phase three - level boost power factor correction converter", Applied power Electronics conference and Exposition APEC, pp. 434 - 439.

iii. Lucanu M., Petrea C.,(2007),"Bridgeless power factor correction converter working at high load variations,” in international symposium on signals, circuits and systems, ISSCS Vol. 2, pp. 1-4.

iv. www.powerstudies.com accessed on $15^{\text {th }}$ August 2013.

v. Read M.B, Seshu S., (1961). "Linear Graphs and Electrical networks”, Addison - Wesley, Reading, M.A,

vi. Ridley R. B. (1989), "Average small - signal analysis of the boost power factor correction circuit" VPEC Seminar proceedings, pp. $800-807$. 